\title{
Enhanced susceptibility to lipopolysaccharide- induced arthritis and endotoxin shock in interleukin-32 alpha transgenic mice through induction of tumor necrosis factor alpha
}

Masanori Nakayama ${ }^{1}$, Yasuo Niki ${ }^{*}$, Toshiki Kawasaki ${ }^{1}$, Yuki Takeda ${ }^{1}$, Keisuke Horiuchi ${ }^{1}$, Aya Sasaki ${ }^{2}$, Yasunori Okada ${ }^{2}$, Kazuo Umezawa ${ }^{3}$, Hiroyasu Ikegami', Yoshiaki Toyama ${ }^{1}$ and Takeshi Miyamoto ${ }^{1}$

\begin{abstract}
Introduction: The present study assessed the potential functions of interleukin (IL)-32 $\alpha$ on inflammatory arthritis and endotoxin shock models using IL-32 $\alpha$ transgenic (Tg) mice. The potential signaling pathway for the IL-32tumor necrosis factor (TNF) $\alpha$ axis was analyzed in vitro.

Methods: IL-32 $\alpha \mathrm{Tg}$ mice were generated under control of a ubiquitous promoter. Two disease models were used to examine in vivo effects of overexpressed IL-32 $\alpha$ : Toll-like receptor (TLR) ligand-induced arthritis developed using a single injection of lipopolysaccharide (LPS) or zymosan into the knee joints; and endotoxin shock induced with intraperitoneal injection of LPS and D-galactosamine. TNF $\alpha$ antagonist etanercept was administered simultaneously with LPS in some mice. Using RAW264.7 cells, in vitro effects of exogenous IL-32 $\alpha$ on TNF $\alpha$, IL-6 or macrophage inflammatory protein 2 (MIP-2) production were assessed with or without inhibitors for nuclear factor kappa B (NF $\kappa$ B) or mitogen-activated protein kinase (MAPK).
\end{abstract}

Results: Single injection of LPS, but not zymosan, resulted in development of severe synovitis with substantial articular cartilage degradation in knees of the Tg mice. The expression of TNF $\alpha$ mRNA in inflamed synovia was highly upregulated in the LPS-injected Tg mice. Moreover, the Tg mice were more susceptive to endotoxininduced lethality than the wild-type control mice 48 hours after LPS challenge; but blockade of TNF $\alpha$ by etanercept protected from endotoxin lethality. In cultured bone marrow cells derived from the Tg mice, overexpressed IL-32 $\alpha$ accelerated production of TNF $\alpha$ upon stimulation with LPS. Of note, exogenously added IL$32 \alpha$ alone stimulated RAW264.7 cells to express TNF $\alpha$, IL-6, and MIP-2 mRNAs. Particularly, IL-32 $\alpha$-induced TNF $\alpha$, but not IL-6 or MIP-2, was inhibited by dehydroxymethylepoxyquinomicin (DHMEQ) and U0126, which are specific inhibitors of nuclear factor kappa B (NF $\kappa$ B) and extracellular signal regulated kinase1/2 (ERK1/2), respectively.

Conclusions: These results show that IL-32 $\alpha$ contributed to the development of inflammatory arthritis and endotoxin lethality. Stimulation of TLR signaling with LPS appeared indispensable for activating the IL-32 $\alpha$-TNF $\alpha$ axis in vivo. However, IL-32 $\alpha$ alone induced TNF $\alpha$ production in RAW264.7 cells through phosphorylation of inhibitor kappa B $(\mid \kappa \mathrm{B})$ and ERK1/2 MAPK. Further studies on the potential involvement of IL-32 $\alpha$-TNF $\alpha$ axis will be beneficial in better understanding the pathology of autoimmune-related arthritis and infectious immunity.

\footnotetext{
* Correspondence: y.niki@lib.bekkoame.ne.jp

'Department of Orthopaedic Surgery, Keio University, 35 Shinanomachi,

Shinjuku, Tokyo 160-8582, Japan

Full list of author information is available at the end of the article
} 


\section{Introduction}

Interleukin-32 (IL-32) was originally identified as natural killer (NK) transcript 4, which is induced by IL-18 in NK cells [1]. NK transcript 4 showed cytokine-like characteristics and played a critical role in inflammation and was therefore renamed IL-32. This cytokine is reportedly produced by NK cells, $\mathrm{T}$ cells, epithelial cells, monocytes, and fibroblasts after stimulation by IL-2, IL-12, and IL-18 and interferon-gamma [2]. Initially, four isoforms of IL-32 (IL-32 $\alpha, \beta, \gamma$, and $\delta$ ) derived from alternative splicing of a single gene. Among these, IL-32 $\alpha$ is the shortest transcript, whereas IL-32 $\gamma$ is the longest isoform and has the strongest biological activity $[2,3]$. Two additional isoforms, IL- $32 \varepsilon$ and $\zeta$, have recently been identified, but these isoforms are not ubiquitously expressed except in T cells [4].

IL-32 has been shown to exhibit properties typical of a proinflammatory cytokine and to drive the induction of other proinflammatory cytokines and chemokines, such as tumor necrosis factor-alpha (TNF $\alpha$ ) and IL-1, IL-6, and IL-8. Owing to such proinflammatory properties, IL-32 has been considered to play a key role in the development of various inflammatory diseases, including rheumatoid arthritis (RA), inflammatory bowel disease [5], mycobacterial $[6,7]$ or viral $[8-10]$ infection, chronic obstetric pulmonary disease [11], and pancreatic tumor $[12,13]$. Although no receptor or analog of IL-32 has yet been identified in mice, human IL-32 reportedly exerts proinflammatory effects as an inducer of TNF $\alpha$ and other inflammatory cytokines in mice both in vitro and in vivo [2,14-16].

During the last decade, TNF $\alpha$ and IL- 6 became widely perceived as substantial therapeutic targets in RA given that the use of either anti-TNF $\alpha$ or anti-IL- 6 therapy could successfully control chronic inflammation in RA. As IL-32 is capable of inducing TNF $\alpha$ and IL-6, this cytokine is increasingly becoming a focus as a potential therapeutic target in RA and other inflammatory disorders. Mounting evidence regarding upstream signaling regulators for IL-32 production has been accumulating in the literature [12,17-20]. However, signaling pathways that are downstream of IL-32 and that lead to TNF $\alpha$ production have yet to be fully elucidated. Most investigators advocate the position that IL-32 augments Toll-like receptor (TLR) signaling, and TLR-2, -3 , and -4 are associated with the effects of IL-32 signaling, although the detailed mechanisms remain to be clarified. Only a few studies to date have reported the implications of mitogen-activated protein kinase (MAPK) or nuclear factor kappa B (NF- $\kappa \mathrm{B})$ pathways in IL-32 signaling [2,21-23].

The present study generated IL-32 $\alpha$ transgenic (Tg) mice that overexpressed human IL-32 $\alpha$ under a control of ubiquitous CAG promoter, and it assessed the in vivo effects of IL-32 $\alpha$ on TLR signaling in the induction of arthritis and endotoxin shock models using the Tg mice. In addition, the potential signaling pathway of the IL$32 \alpha-\mathrm{TNF} \alpha$ axis was analyzed in vitro.

\section{Materials and methods \\ Reagents}

Lipopolysaccharide (LPS) from Escherichia coli 0111:B4 and zymosan A from Saccharomyces cerevisiae were purchased from Sigma-Aldrich (St. Louis, MO, USA), and D-galactosamine was purchased from Wako Pure Chemical Industries (Osaka, Japan). Etanercept was obtained from Wyeth (Tokyo, Japan). Recombinant human IL-32 $\alpha$ protein (rIL-32 $\alpha$ ) was obtained from Takara Bio (Shiga, Japan). IL-32 $\alpha$-specific enzyme-linked immunosorbent assay (ELISA) (Human IL-32 $\alpha$ ELISA MAX Deluxe Set) was purchased from BioLegend (San Diego, CA, USA), and TNF $\alpha$-specific ELISA (Quantikine Mouse TNF $\alpha$ ) and anti-IL-32 $\alpha$ antibody were purchased from R\&D Systems (Minneapolis, MN, USA). All other antibodies were purchased from Cell Signaling Technology Japan (Tokyo, Japan). Dehydroxymethylepoxyquinomicin (DHMEQ) (an inhibitor for NF- $\kappa \mathrm{B}$ ) was provided as previously described [24,25]. MAPK inhibitors U0126, SB203580, and SP600125 - which are inhibitors for ERK1/2, p38, and JNK, respectively - were purchased from SigmaAldrich. DHMEQ and MAPK inhibitors were dissolved in $100 \%$ dimethyl sulfoxide (DMSO) at $100 \mathrm{mg} / \mathrm{mL}$ and were stored in aliquots at $-30^{\circ} \mathrm{C}$. Before use in cell culture, they were diluted with the medium to a final DMSO concentration of not more than $0.05 \%$.

\section{Real-time polymerase chain reaction analysis}

Total RNAs were isolated from each sample by RNAiso plus (Takara Bio), and cDNAs were synthesized from total RNAs by using a PrimeScript RT reagent Kit (Takara Bio). Real-time polymerase chain reaction (PCR) was performed by using SYBR Premix ExTaq II (Takara Bio) with a DICE Thermal cycler (Takara Bio) in accordance with the instructions of the manufacturer. Results were normalized to glyceraldhyde-3-phosphate dehydrogenase (GAPDH) as the fold change compared with samples. The primer sequences used in this study are presented in Table 1.

\section{Immunoblot analysis}

Mice organs or cell lysates were prepared by using RIPA buffer: $1 \%$ Triton X-100, $1 \%$ sodium deoxycholate, $0.1 \%$ SDS, $150 \mathrm{mM} \mathrm{NaCl}, 10 \mathrm{mM}$ Tris- $\mathrm{HCl}, \mathrm{pH}$ 7.5, $5 \mathrm{mM}$ ethylenediaminetetraacetic acid (EDTA), and a protease inhibitor cocktail. An equal volume of protein from each lysate was separated by SDS-PAGE, and separated proteins were transferred to nitrocellulose membranes. After transfer, the membrane was blocked with 5\% non-fat dried skim milk for 1 hour at room temperature and then incubated with the primary antibody against the 


\begin{tabular}{|c|c|c|}
\hline Primer & Sense & Sequence \\
\hline \multirow[t]{2}{*}{ Mouse GAPDH } & Forward & 5'-CTTTGTCAAGCTCATTTCCTGG-3' \\
\hline & Reverse & 5'-TCTTGCTCAGTGTCCTTGC-3' \\
\hline \multirow[t]{2}{*}{ Human IL-32 $\alpha$} & Forward & 5'-CCTTGGCTCCTTGAACTITTG-3' \\
\hline & Reverse & 5'-CTGTCCACGTCCTGATTCTG-3' \\
\hline \multirow[t]{2}{*}{ Mouse TNF $\alpha$} & Forward & 5'-CTTCTGTCTACTGAACTTCGGG-3' \\
\hline & Reverse & 5'-CAGGCTTGTCACTCGAATITTG-3' \\
\hline \multirow[t]{2}{*}{ Mouse IL-6 } & Forward & 5'-CAAAGCCAGAGTCCTTCAGAG-3' \\
\hline & Reverse & 5'-GTCCTTAGCCACTCCTTCTG-3' \\
\hline \multirow[t]{2}{*}{ Mouse MIP-2 } & Forward & 5'-GAAGTCATAGCCACTCTCAAGG-3' \\
\hline & Reverse & 5'-CTTCCGTTGAGGGACAGC-3' \\
\hline
\end{tabular}

GAPDH, glyceraldhyde-3-phosphate dehydrogenase; IL, interleukin; MIP-2, macrophage inflammatory protein $2 ; \mathrm{TNF} \alpha$, tumor necrosis factor-alpha.

target molecule overnight. Next, the membrane was incubated with horseradish peroxidase-conjugated secondary antibody for 1 hour at room temperature. After washing, protein was detected by using an enhanced chemiluminescence (ECL) system. The same membrane was then stripped by Tris-HCL (62.5 mM), 2\% SDS, and $\beta$-mercaptoethanol and blocked with skim milk and incubated with primary antibody against another molecule, following the same procedure mentioned above.

\section{Generation of human IL-32 $\alpha$ transgenic mice}

We generated IL-32 $\alpha \mathrm{Tg}$ mice, which overexpressed human IL-32 $\alpha$ under a control of a ubiquitous CAG promoter constructed by the first intron of the chicken $\beta$-actin gene and a portion of the rabbit $\beta$-globin gene [26]. The background of these mice was C57BL/6 Jcl (obtained from CLEA Japan, Tokyo, Japan). Wild-type C57BL/6 Jcl (Wt) mice were also obtained from CLEA Japan. All mice were 18 to 20 weeks old when they were used. All animal experiments were conducted in accordance with institutional and national guidelines. IL-32 $\alpha$ insertion was confirmed by amplification of the genome DNA isolated from mouse organs by using realtime PCR. The reason real-time PCR was employed was that we wanted to simultaneously detect and quantify transgene-derived IL-32 $\alpha$ in multiple organs of Tg mice. The amount of TNF $\alpha$ expression in multiple organs was measured by real-time PCR. IL-32 $\alpha$ protein in multiple organs was detected by immunoblot analysis. Levels of IL-32 $\alpha$ in blood serum, knee, and liver lysate were measured by specific ELISA.

\section{Inflammatory arthritis model}

Inflammatory arthritis was induced as described previously [27-29]. As in these reports, intra-articular injection of LPS was employed in IL-32 $\alpha \mathrm{Tg}$ mice to elucidate the arthritogenic capacity of IL-32 $\alpha$. Knees of Tg and Wt mice were injected once with LPS $(1 \mu \mathrm{g}$, much less than the reported amount $[27,28])$ or zymosan $(20 \mu \mathrm{g}$, much less than the reported amount [29]) without any other material as a booster. Injection of phosphate-buffered saline (PBS) served as a control to the contralateral knee of the same mouse. Two weeks after injection, a histopathological examination was performed, and TNF $\alpha$ mRNA expression in synovia of knees was quantitatively measured by using real-time PCR.

\section{Endotoxin shock model}

Endotoxin shock was induced by intraperitoneal injections of $5 \mu \mathrm{g}$ of LPS and $10 \mathrm{mg}$ of D-galactosamine [30]. Half of the mice were injected with $100 \mu \mathrm{g}$ of etanercept at the same time. All injected mice were closely monitored every hour for the first 16 hours and every 3 to 6 hours thereafter for 48 hours. In an additional experiment, we sacrificed mice at 1,3 , and 6 hours after intraperitoneal injection and extracted the liver, spleen, and blood serum. TNF $\alpha$ mRNA of liver and spleen lysates was measured by real-time PCR, and serum TNF $\alpha$ was measured by ELISA.

\section{Cell culture}

Bone marrow (BM) was extracted from the leg bones of Tg or Wt mice and cultured for 72 hours in alpha-minimum essential medium (Sigma-Aldrich) containing 10\% fetal calf serum (FCS), $100 \mathrm{U} / \mathrm{mL}$ penicillin, $100 \mathrm{mg} / \mathrm{mL}$ streptomycin, and 1\% Gluta Max (Gibco Invitrogen, Carlsbad, CA, USA) supplemented with macrophage colony-stimulating factor (50 ng/mL; Kyowa Hakko Kirin, Tokyo, Japan). RAW 264.7 cells were cultured in Dulbecco's modified Eagle's medium (high-glucose) (Gibco Invitrogen) containing $10 \% \mathrm{FCS}, 100 \mathrm{U} / \mathrm{mL}$ penicillin, and $100 \mu \mathrm{g} / \mathrm{mL}$ streptomycin.

\section{Stimulation of cells}

BM cells from Tg and Wt mice $\left(10^{6}\right.$ cells) were incubated under stimulation of LPS (50 ng/mL) for 1, 3, 6, and 24 hours, and the amount of TNF $\alpha$ was measured by realtime PCR. TNF $\alpha$ concentration in culture media of BM cells $\left(10^{5}\right.$ cells) after 24 -hour incubation with LPS $(5,10$, or $50 \mathrm{ng} / \mathrm{mL}$ ) was measured by specific ELISA. RAW 264.7 cells $\left(2 \times 10^{4}\right.$ cells $)$ were cultured with rIL-32 $\alpha$ or LPS for 24 hours, and the TNF $\alpha$ concentration in culture media was measured by ELISA. For the analysis of signaling pathway, RAW 264.7 cells $\left(2 \times 10^{4}\right.$ cells $)$ were stimulated with rIL-32 $\alpha$ in combination with the specific inhibitors of NF- $\kappa \mathrm{B}$ and MAPKs, such as DHMEQ (0.4, 2, or $10 \mu \mathrm{g} / \mathrm{mL})$, U0126 (0.2, 1, or $5 \mu \mathrm{M})$, SB203580 (0.2, 1 , or $5 \mu \mathrm{M})$, and SP600125 $(0.4$, 2, or $10 \mu \mathrm{M})$. DMSO (final concentration of $0.05 \%$ ) served as a control. After 24 hours of culture, the level of TNF $\alpha$ in culture media was measured by ELISA. For immunoblot analysis, RAW 264.7 cells $\left(2 \times 10^{6}\right.$ cells $)$ were cultured with rIL-32 $\alpha$ for 
$5,10,30,60,90,120$, or 180 minutes, followed by washing with ice-cold PBS and lysis in RIPA detergent buffer. The resultant cell lysates were then immunoblotted by using affinity-purified antibodies against phospho- $\mathrm{I} \kappa \mathrm{B}$, $\mathrm{I} \kappa \mathrm{B}$, phospho-ERK1/2, ERK1/2, phospho-p38, p38, phospho-JNK, JNK, and $\beta$-actin. mRNA expressions for IL-6 and macrophage inflammatory protein 2 (MIP-2) as well as TNF $\alpha$ in IL-32-stimulated RAW 264.7 cells $\left(2 \times 10^{4}\right.$ cells) were measured by real-time PCR, and the inhibitory effects of specific signaling inhibitors, including DHMEQ, U0126, SB203580, and SP600125, were analyzed.

\section{Statistical analysis}

Results are reported as the mean \pm standard deviation. Statistical analysis was undertaken by using a two-tailed Student $t$ test. Differences were considered statistically significant at a $P$ value of less than 0.05 . The endotoxin shock model was graphed in Kaplan-Meier format and analyzed by a log-rank test. All experiments were performed in three or four times.

\section{Results}

\section{Generation of human IL-32 $\alpha$ transgenic mice}

Human IL-32 $\alpha$ Tg mice were designed to overexpress human IL- $32 \alpha$ by using CAG promoter. Of seven F0 mice, two mice expressing sufficient levels of IL-32 $\alpha$ mRNA were used to establish lines. The F0 mice and all offspring exhibited no evident pathological phenotype, had a normal body weight, and developed and bred normally. Real-time PCR analysis of the Tg mouse lines demonstrated high levels of IL-32 $\alpha$ mRNA expression in a variety of organs, prominently in the knee joint and cardiac muscle (Figure 1a). Transgene-derived IL-32 $\alpha$

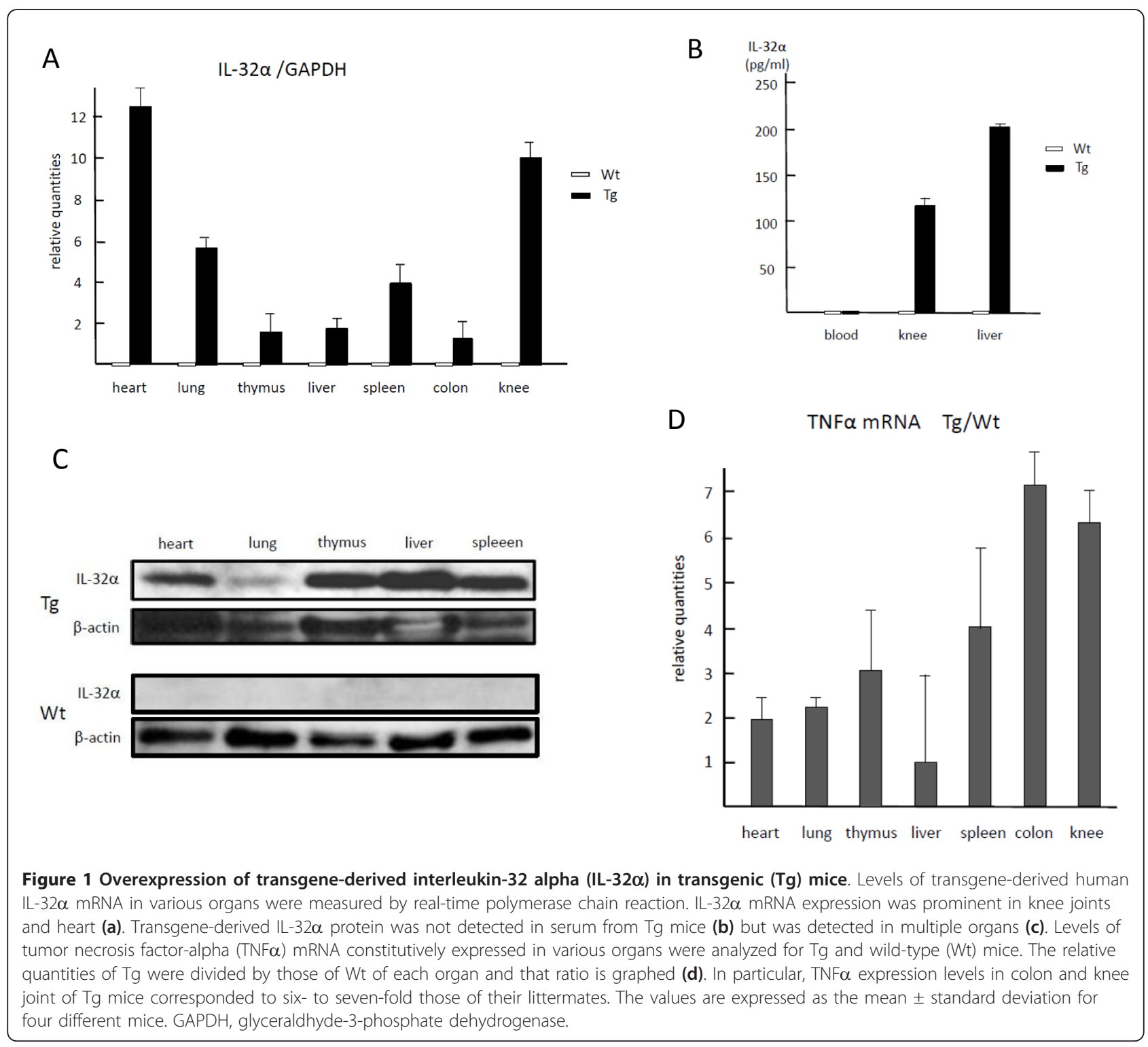


protein could be detected in multiple organs (Figure 1b, c) but not in serum from Tg mice (Figure 1b). This result might be because the IL-32 $\alpha$ isotype has been reported to remain intracellularly [2]. Constitutive expression of TNF $\alpha$ mRNA induced by overexpressed IL-32 $\alpha$ was apparent in most organs, and expression levels in the colon and knee joint from Tg mice reached six to seven times the levels seen in littermates (Figure 1d).

\section{Single intra-articular injection of LPS, but not zymosan, induced inflammatory synovitis and cartilage degradation in transgenic mice}

Mice were sacrificed 2 weeks after a single injection of LPS or zymosan, followed by a histopathological examination of the knee joints. The results indicated that the single injection of LPS, but not zymosan, resulted in the development of severe synovitis with articular cartilage destruction in the knees of Tg mice. Such LPS-induced arthritis did not occur in the knees of Wt mice or in contralateral knees injected with PBS (Figure 2a). The level of TNF $\alpha$ mRNA expressed in inflamed synovia after LPS injection was significantly higher in Tg mice than in Wt mice (Figure 2b).
Transgenic mice exhibited severe endotoxin lethality after LPS challenge

As a single intraperitoneal injection of LPS with D-galactosamine has been perceived to be capable of inducing endotoxin shock in mice, the impacts of constitutive expression of IL-32 $\alpha$ and subsequently produced TNF $\alpha$ on endotoxin lethality were investigated. Mice receiving an intraperitoneal injection of LPS started to die in 5 hours, and the survival rates at 48 hours after injection were $41 \%$ for $\mathrm{Tg}$ mice and $75 \%$ for Wt mice (Figure 3a), showing statistical significance $(P<0.05)$. Importantly, blockade of TNF $\alpha$ by simultaneous administration of etanercept protected from endotoxin shock and markedly increased survival rate in both Tg and Wt mice, suggesting that IL-32-induced TNF $\alpha$ played a key role in developing endotoxin shock. TNF $\alpha$ mRNA expression in liver and spleen peaked at 1 hour after injection and at much higher levels than those of Wt mice $(P<0.01)$ (Figure $3 \mathrm{~b}$, c). A similar temporal course was observed for the level of TNF $\alpha$ protein in serum (Figure 3d). At 1 hour after injection, levels of TNF $\alpha$ mRNA in the liver and spleen and TNF $\alpha$ protein in serum were significantly higher in Tg mice than in Wt mice $(P<0.05)$.
A

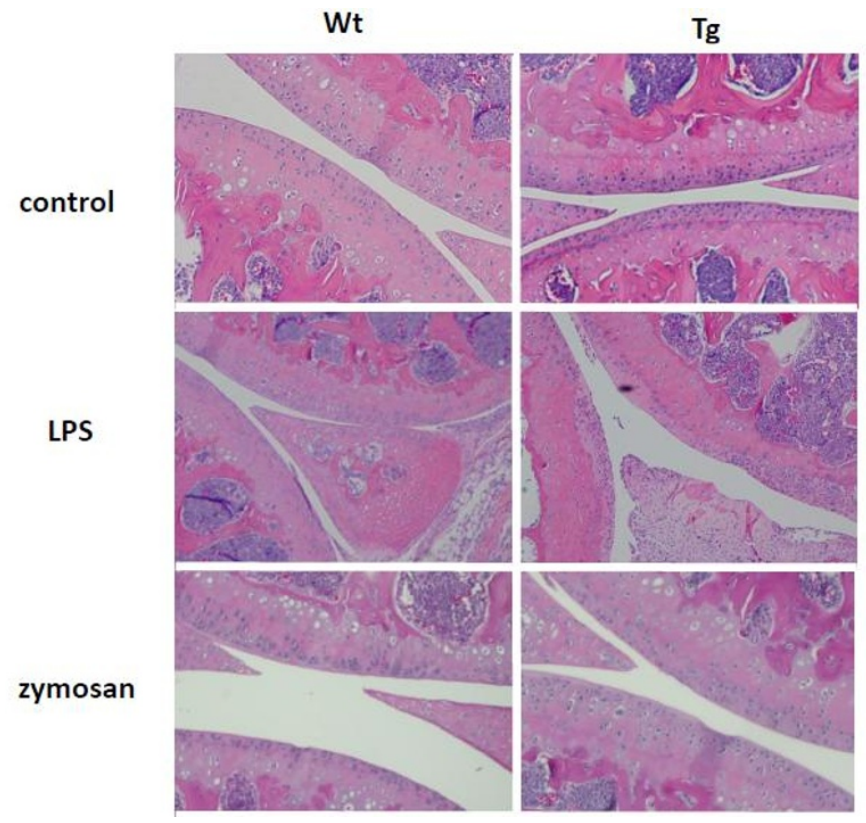

B

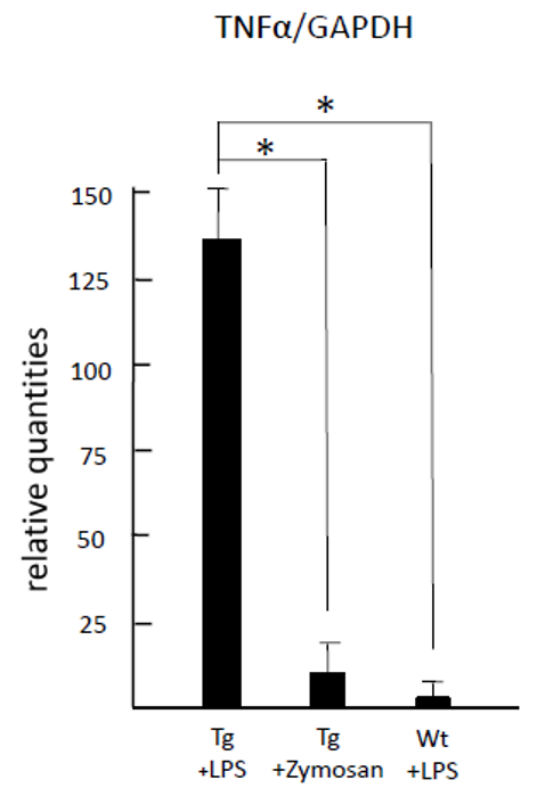

Figure 2 Inflammatory arthritis induced by single intra-articular injection of lipopolysaccharide (LPS) in transgenic (Tg) mice. One microgram of LPS or $20 \mu \mathrm{g}$ of zymosan was injected into the knee joints of Tg and wild-type (Wt) mice. Histopathologically, severe synovitis with articular cartilage destruction was observed 2 weeks after injection in Tg mice injected with LPS but not in Tg mice injected with zymosan or phosphate-buffered saline or in Wt mice $(\times 100)($ a). The level of tumor necrosis factor-alpha (TNF $\alpha)$ mRNA expressed in inflamed synovia was significantly higher in Tg mice injected with LPS than in Tg mice injected with zymosan or in Wt mice injected with LPS (*P < 0.01) (b). The values are expressed as the mean \pm standard deviation for four different mice. GAPDH, glyceraldhyde-3-phosphate dehydrogenase. 
A

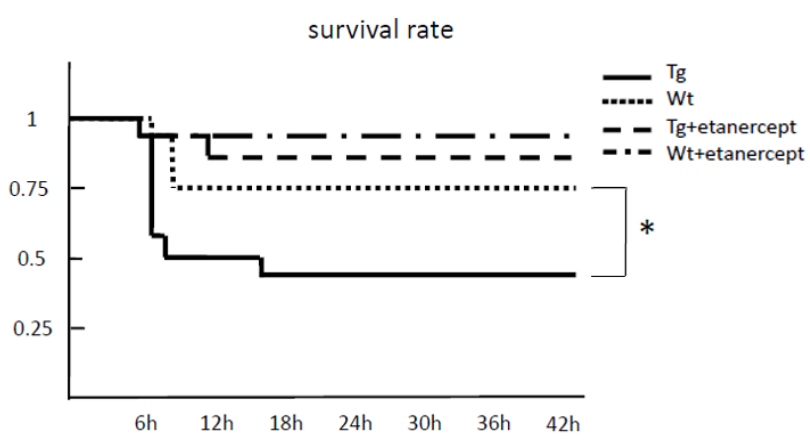

C

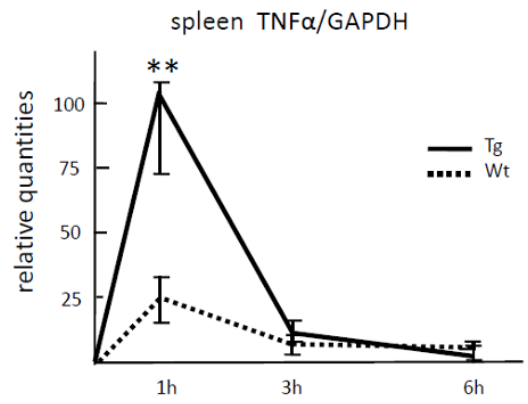

B

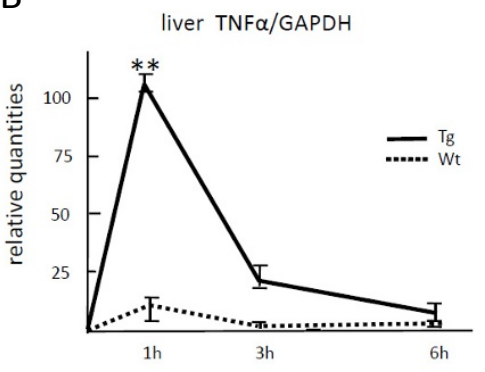

D

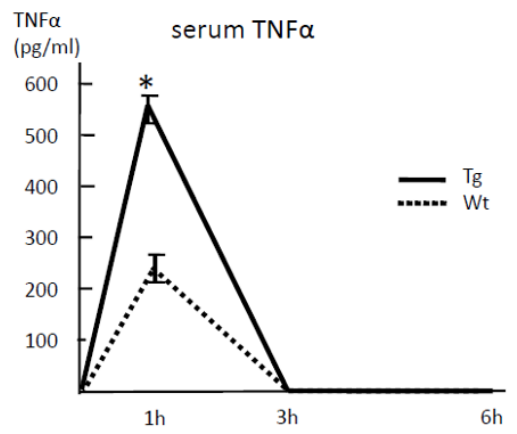

Figure 3 Interleukin-32 alpha overexpression in mice increased the lethality of lipopolysaccharide (LPS)-induced endotoxin shock Endotoxin shock was induced in both transgenic $(\mathrm{Tg})$ mice $(n=24)$ and wild-type $(\mathrm{Wt})$ mice $(n=24)$ by intraperitoneal injection of LPS with Dgalactosamine. Twelve mice of each group were simultaneously administered etanercept. All mice were monitored for survival up to 48 hours. Survival rate was significantly worse in the Tg group than in the Wt group $\left({ }^{*} P<0.05\right)$. Etanercept protected against endotoxin shock in both groups (a). Temporal changes in TNF $\alpha$ levels were measured by real-time polymerase chain reaction for liver and spleen lysate or. enzyme-linked immunosorbent assay for blood serum. Levels of tumor necrosis factor-alpha (TNF $\alpha$ ) mRNA and protein peaked at 1 hour after LPS injection in the liver (b), spleen (c), and serum (d) from Tg and Wt mice, but levels were much higher in Tg mice than in Wt mice $\left.{ }^{*} P<0.05,{ }^{* *} P<0.01\right)$. The values are expressed as the mean \pm standard deviation for four different mice. GAPDH, glyceraldhyde-3-phosphate dehydrogenase.

\section{Endogenously overexpressed IL-32 $\alpha$ accelerated production of TNF $\alpha$ upon stimulation with LPS}

To examine the effects of endogenous IL-32 $\alpha$ on TNF $\alpha$ production in vitro, BM macrophages derived from IL-32 $\alpha$ $\mathrm{Tg}$ and Wt mice were used. The level of TNF $\alpha$ mRNA expression was significantly higher in $\mathrm{Tg}$ mice than in $\mathrm{Wt}$ mice after stimulation with LPS $(P<0.05)$. Temporal changes in TNF $\alpha$ mRNA expression revealed that the level of TNF $\alpha$ mRNA peaked at 3 hours after LPS stimulation and gradually decreased with time (Figure 4a). LPS increased TNF $\alpha$ secretion into culture media in a dosedependent manner, and the amounts of TNF $\alpha$ produced by BM macrophages were universally higher in $\mathrm{Tg}$ mice than in Wt mice throughout all doses of LPS tested (Figure 4b).

\section{Exogenous IL-32 $\alpha$ enhanced TNF $\alpha$ production in RAW} 264.7 cells through NF- $\kappa$ B and ERK1/2 signaling pathways To elucidate the effects of exogenous IL- $32 \alpha$ on TNF $\alpha$ production in vitro, rIL-32 $\alpha$ was added to RAW 264.7 cells in culture. Although RAW 264.7 cells constitutively produced substantial amounts of TNF $\alpha$, rIL-32 $\alpha$ alone as well as LPS could further stimulate RAW 264.7 cells to produce TNF $\alpha$ (Figure 5a). DHMEQ and U0126, as inhibitors of NF- $\kappa \mathrm{B}$ and ERK1/2, respectively, reduced IL$32 \alpha$-induced TNF $\alpha$ production in a dose-dependent manner, whereas SB203580 and SP600125, as inhibitors of p38 and JNK, respectively, did not (Figure 5b). Immunoblot analysis revealed that exogenous IL-32 $\alpha$ clearly phosphorylated $\mathrm{I} \kappa \mathrm{B}$ and ERK1/2, both starting at $30 \mathrm{~min}-$ utes and peaking at 90 minutes for ERK1/2 and at 120 minutes for $\mathrm{I} \kappa \mathrm{B}$, whereas significant phosphorylation was not observed in p38 or JNK (Figure 5c). These results supported the finding that DHMEQ and U0126, but not SB203580 and SP600125, inhibited IL-32 $\alpha$-induced TNF $\alpha$ production. Consequently, exogenous IL-32 $\alpha$ induced TNF $\alpha$ production was mediated predominantly through the activation of NF- $\kappa \mathrm{B}$ and the MEK-ERK signaling pathway. 
A

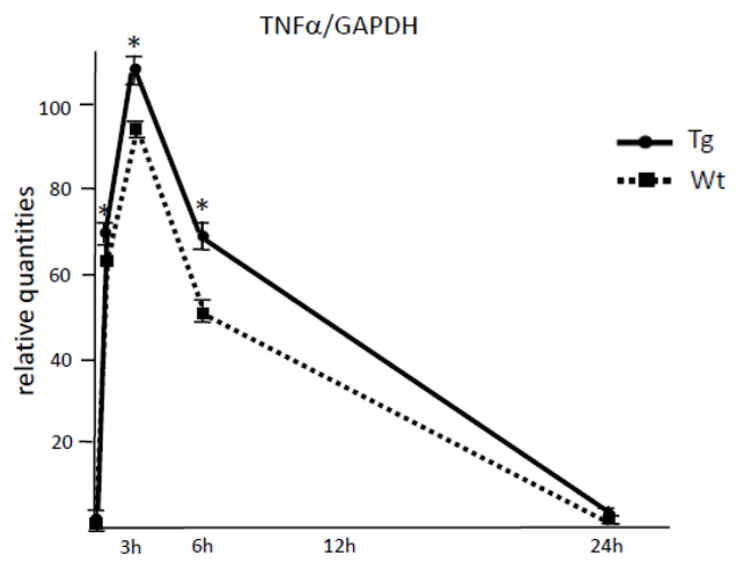

B

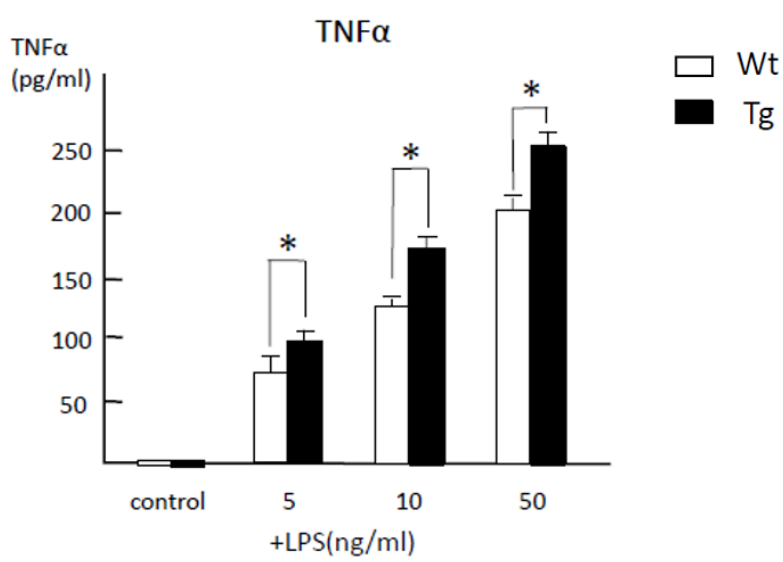

Figure 4 Bone marrow (BM) macrophages from transgenic ( $\mathrm{Tg}$ ) mice were stimulated to produce tumor necrosis factor-alpha (TNF $\alpha$ ) upon stimulation with lipopolysaccharide (LPS). Temporal changes in the level of TNF $\alpha$ mRNA expressed by BM macrophages were measured upon stimulation with LPS. TNF $\alpha$ mRNA level peaked at 3 hours and gradually decreased and was significantly higher in Tg mice than in wild-type (Wt) mice over time (a). The amount of TNF $\alpha$ in culture media was measured after 24 hours of LPS stimulation by using a specific enzyme-linked immunosorbent assay (b). LPS stimulated secretion of TNF $\alpha$ from BM macrophages in a dose-dependent manner, and levels were higher in Tg mice than in $\mathrm{Wt}$ mice $\left({ }^{*} P<0.05\right)$. The values are expressed as the mean \pm standard deviation for three different mice. GAPDH, glyceraldhyde-3-phosphate dehydrogenase.

Exogenous IL-32 $\alpha$ stimulated IL- 6 and MIP-2 expression in RAW 264.7 cells independently of NF- $\kappa$ B and MAPK signaling pathways

The effects of exogenous IL- $32 \alpha$ on IL- 6 and MIP-2 production were examined since these cytokines were reportedly induced by IL-32 [3]. rIL-32 $\alpha$ alone stimulated RAW 264.7 cells to express TNF $\alpha$, IL-6, and MIP2 mRNAs to a similar degree. Specific signaling inhibitors, DHMEQ and U0126, suppressed the expression of TNF $\alpha$ mRNAs; however, neither of these two inhibitors affected the expression of IL- 6 and MIP-2 mRNAs induced by IL-32 $\alpha$ (Figure 6), suggesting that a signaling pathway other than NF- $\kappa \mathrm{B}$ and MAPKs might be involved in IL-6 and MIP-2 mRNA expressions.

\section{Discussion}

To date, the arthritogenic role of IL-32 has been elucidated on the basis of accumulated evidence that overexpression of IL-32 $\beta$ in a mouse model using bone transplantation exacerbated collagen-induced arthritis in mice [14] and that intra-articular injection of IL-32 $\gamma$ in mouse knee joints resulted in severe joint inflammation [15]. In this study, although IL-32 $\alpha \mathrm{Tg}$ mice did not spontaneously exhibit any abnormal phenotype, intraarticular injection of low-dose LPS resulted in the development of inflammatory arthritis. However, injection of zymosan was not capable of sufficiently inducing TNF $\alpha$ and subsequent arthritis. As LPS is known as a specific ligand of TLR-4, interaction of IL-32 $\alpha$ with TLR-4 may play a critical role in the development of arthritis, and this was also the case in LPS-triggered endotoxin shock in the Tg mice. This endotoxin shock model provided an excellent means to evaluate the effects of IL-32 $\alpha$ on infectious immunity. In the present study, IL-32 $\alpha$ overproduction in $\mathrm{Tg}$ mice was associated with severe endotoxin lethality; this was shown to be mediated through the induction of TNF $\alpha$, because etanercept significantly attenuated the endotoxin shock.

Although the present study clearly demonstrated that LPS, as a TLR-4 agonist, but not the TLR-2 agonist zymosan, might play a key role in potentiating the proinflammatory activity of IL-32 $\alpha$, how exactly IL-32 $\alpha$ interacted with the TLR-4 signaling pathway remains unclear. Most recently, Heinhuis and colleagues [31] reported that LPS co-stimulation was mandatory to elicit IL-32 bioactivity in THP-1 cells, and the present study obtained similar findings that TNF $\alpha$ production promoted by IL-32 $\alpha$ required co-stimulation with LPS (Figure 4). In terms of the interaction between IL-32 and TLR-2/NOD2 (nucleotide-binding oligomerization domain-containing protein 2) signaling, IL-32 has been reported to stimulate TNF $\alpha$, IL-6, and IL- 8 production by directly increasing expression of TLR-2 and NOD2 [32]. Conversely, the interaction of IL-32 with TLR-4 


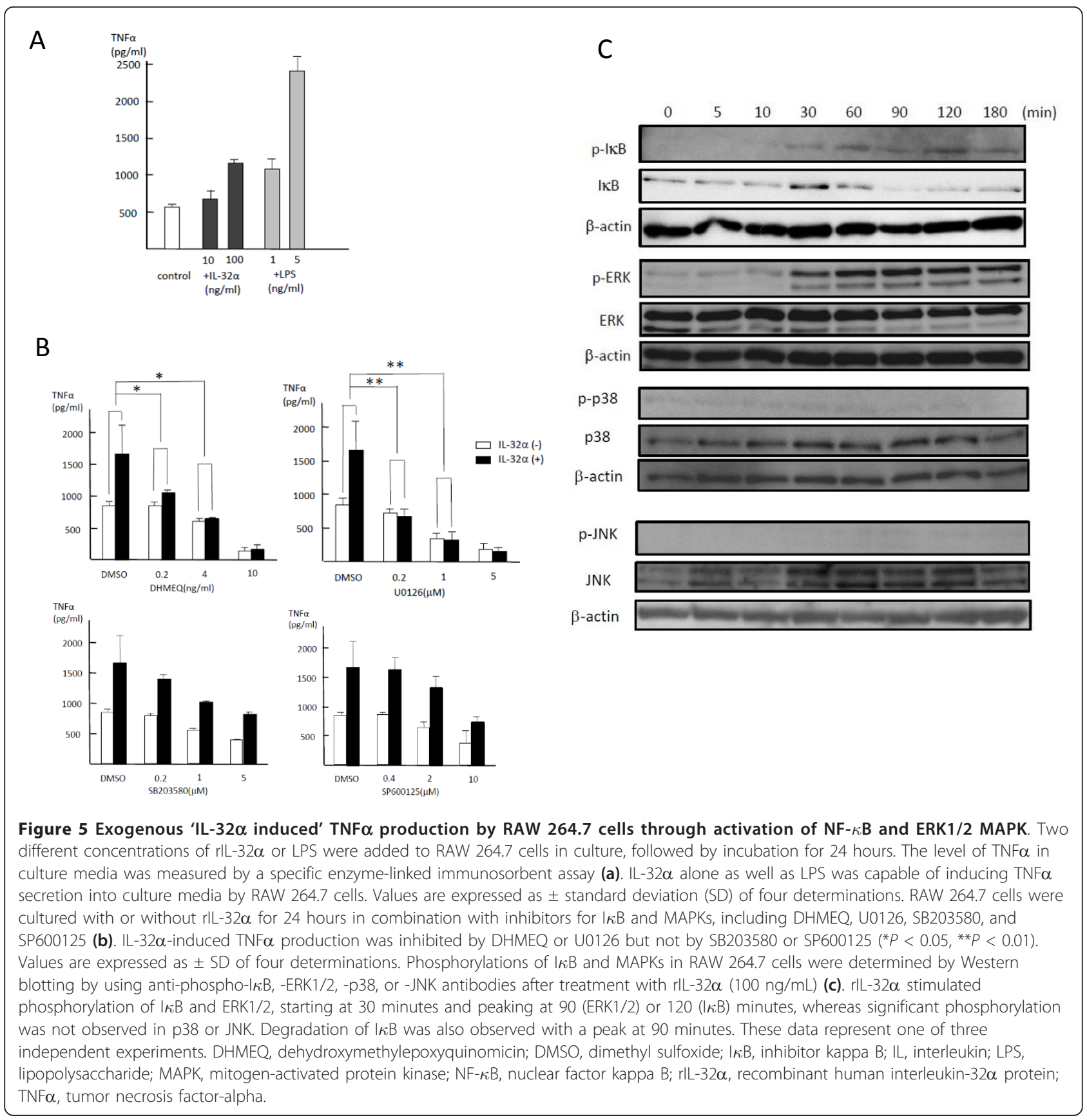

can be speculated to involve the binding of IL-32 to its putative receptor modulates downstream signaling for TLR-4 or other TLRs, since the proinflammatory activities of IL-32 were present even in macrophages derived from TLR $-4^{-1-}$ mice, and stimulation with IL-32 plus TLR ligand elicited only additive effects rather than synergistic effects [33]. Two candidate molecules potentially connecting IL- $32 \alpha$ and TLR- 4 signaling are considered. One is proteinase- 3 and the other is proteinaseactivated receptor 2 (PAR2); the former reportedly acts as an IL-32-binding protein and cleaves all isoforms of
IL-32 to generate a more active form $[34,35]$, and the latter has been shown to be associated with late NF- $\kappa \mathrm{B}$ activation and subsequent TNF $\alpha$ production predominantly through a myeloid differentiation factor 88 (MyD88)-independent pathway [36].

In contrast to mounting evidence on upstream signaling regulators for IL-32, downstream signaling pathways of IL-32 toward TNF $\alpha$ production have not yet been analyzed in detail, and only a small number of reports have focused on different signals in different cell types. The first report of IL-32 advocated that IL-32 $\alpha$ 
A

TNF $\alpha /$ GAPDH

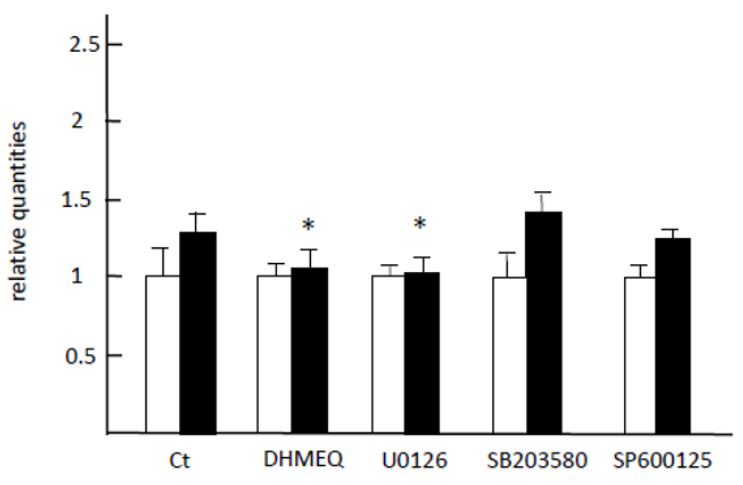

C

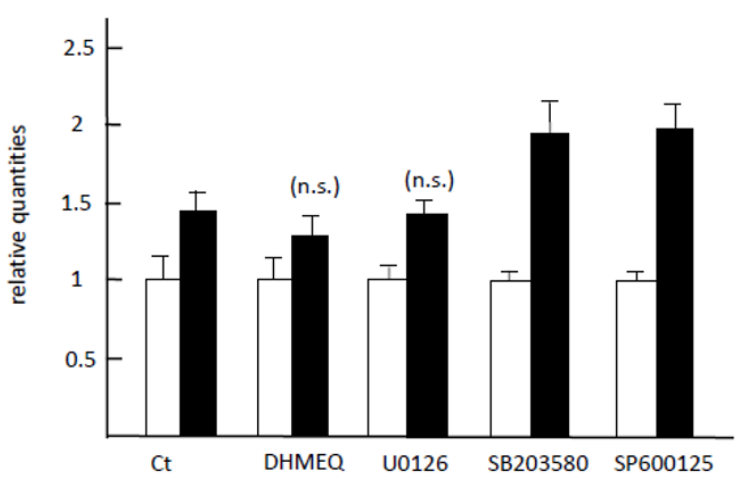

B

IL-6/GAPDH

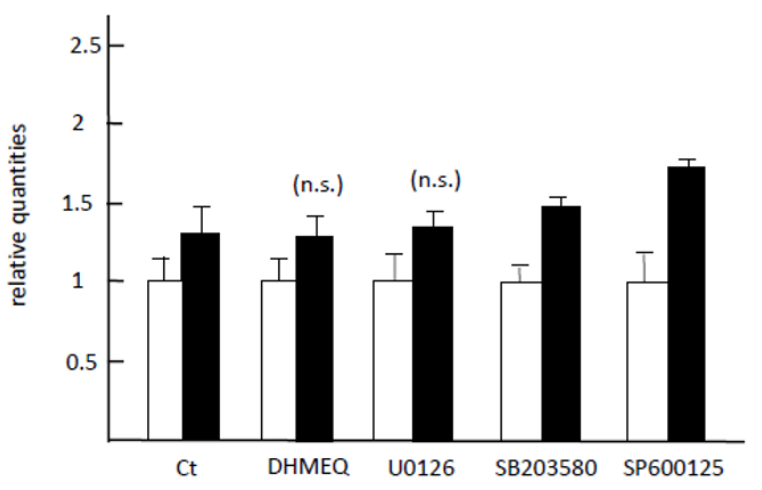

$\square$ IL-32 $2(-)$

Figure 6 Exogenous IL- $32 \alpha$ stimulated mRNA expression of IL- 6 and MIP-2 independently of NF- $\kappa$ B and MAPK signaling pathways. RAW 264.7 cells were stimulated with rlL-32 $\alpha$ in combination with inhibitors for $1 \kappa B$ and MAPKs, including DHMEQ, U0126, SB203580, and SP600125, for 6 hours. The amounts of mRNA of TNF $\alpha$ (a), IL-6 (b), and MIP-2 (c) were measured by real-time polymerase chain reaction. rlL-32 $\alpha$ alone stimulated RAW 264.7 cells to express IL-6 and MIP-2 as well as TNF $\alpha$ at the mRNA level. None of the inhibitors canceled IL-6 and MIP-2 mRNA expression induced by IL-32 $\alpha$, whereas DHMEQ and U0126 suppressed TNF $\alpha$ mRNA expression. Values are expressed as mean \pm standard deviation of triplicate determinations. Ct, control; DHMEQ, dehydroxymethylepoxyquinomicin; GAPDH, glyceraldhyde-3-phosphate

dehydrogenase; $I \kappa B$, inhibitor kappa B; IL, interleukin; LPS, lipopolysaccharide; MAPK, mitogen-activated protein kinase; MIP-2, macrophage inflammatory protein 2; NF- $\kappa \mathrm{B}$, nuclear factor kappa B; n.S., not significant; rlL-32 $\alpha$, recombinant human interleukin-32 $\alpha$ protein; TNF $\alpha$, tumor necrosis factor-alpha.

stimulated TNF $\alpha$ production through activation of NF$\kappa \mathrm{B}$ and $\mathrm{p} 38$ MAPK in mouse RAW 267.4 cells; the two peaks of p38 MAPK phosphorylation at 5 and $45 \mathrm{~min}$ utes were considered a characteristic finding for this cytokine [2]. Netea and colleagues [21] subsequently reported that IL-32-induced TNF $\alpha$ production by human peripheral blood mononuclear cells (PBMCs) was similarly regulated through phosphorylation of p38 MAPK. On the other hand, ERK1/2 MAPK was dominant in IL-32-induced osteoclastogenesis for human PBMCs [22] and in IL-32-induced IL-6 and IL-8 production by human fibroblast-like synoviocytes [23]. The present study demonstrated that IL-32 $\alpha$-induced TNF $\alpha$ production was mediated through phosphorylation of
$\mathrm{I} \kappa \mathrm{B}$ and ERK1/2 in RAW 267.4 cells. Actually, all three components of MAPKs - p38, JNK, and ERK1/2 - were constitutively phosphorylated in RAW 267.4 cells; however, only ERK1/2 phosphorylation was significantly accelerated in response to IL-32 $\alpha$ stimulation. This observation corroborated the fact that the addition of inhibitors for ERK1/2 and NF- $\kappa$ B suppressed each phosphorylation (data not shown and Figure S1 of Additional file 1 ) and consequently canceled IL-32 $\alpha$-induced upregulation of TNF $\alpha$ at the mRNA level (Figures $5 \mathrm{~b}$ and 6 ). Given the delayed phosphorylation of $\mathrm{I} \kappa \mathrm{B}$ and ERK1/2 starting at 30 minutes in this study, IL- $32 \alpha$ in RAW 267.4 cells might not directly activate $\mathrm{I} \kappa \mathrm{B}$ or ERK $1 / 2$. Instead, other molecules might play an important role 
in $\mathrm{I} \kappa \mathrm{B}$ or ERK $1 / 2$ activation of IL-32 $\alpha$, or the IL-32 $\alpha$ TNF $\alpha$ axis might use the MyD88-independent pathway reportedly associated with the late inflammatory response of TLR-4 [37]. Our study also revealed that IL$32 \alpha$ induced IL- 6 and MIP- 2 as well as TNF $\alpha$, but their induction was not canceled by inhibitors for NF- $\kappa \mathrm{B}$ or MAPKs. This observation indicates that a signaling pathway other than NF-kB or MAPKs might be involved in IL-6 and MIP-2 expressions.

IL-32 $\gamma \mathrm{Tg}$ mice obtained by using a promoter similar to that of the present study reportedly exhibited no apparent phenotype, but once inflammatory colitis was induced with dextran sodium sulfate (DSS) in the Tg mice, severe colitis occurred within 4 days [38]. Interestingly, at more than 6 days after DSS challenge, the degree of colonic inflammation in the Tg mice was significantly reduced, and recovery was more rapid than that in Wt mice because of increased IL-10 levels in serum. In another study, IL-32 $\beta$ was reported to promote the production of IL-10 in human cell lines [39]. According to our data on RAW 264.7 cells, the level of TNF $\alpha$ in culture media peaked at 12 hours after stimulation with IL- $32 \alpha$ and gradually decreased thereafter, whereas IL-10 levels increased from 24 to 96 hours after stimulation (data not shown and Figure S2 of Additional file 2). IL-32 is thus considered to represent a cytokine possessing contradictory properties according to the different phases of the disease. Such paradoxical effects of IL-32 were not observed in our Tg mice. In fact, a single intra-articular injection of LPS in our Tg mice resulted in a transient flare of inflammatory arthritis, characterized by neutrophil infiltration and synovial proliferation, but such inflammation might cease within 2 weeks, followed by amelioration of synovitis with only mild cartilage erosion remaining. On the other hand, the endotoxin shock model using our $\mathrm{Tg}$ mice was suitable for examining short-term effects, but not long-term effects, of IL-32 in vivo since most mice died within several hours after LPS challenge, and TNF $\alpha$ induced by IL-32 $\alpha$ and LPS was confirmed as an early mediator of endotoxin lethality [40]. The time-dependent and complicated regulation of IL-32 and the relevant molecules of the IL-32-TNF $\alpha$ axis during the course of autoimmune-related arthritis and infectious immunity should be elucidated in future studies.

\section{Conclusions}

This study revealed that IL- $32 \alpha$ contributed to the development of LPS-induced inflammatory arthritis and endotoxin lethality; therefore, stimulation of LPS appears indispensable for activating the IL-32-TNFa axis in vivo. However, IL-32 $\alpha$ alone induced TNF $\alpha$ production in RAW 264.7 cells through phosphorylation of $\mathrm{I} \kappa \mathrm{B}$ and ERK1/2 MAPK.

\section{Additional material}

Additional file 1: Figure S1. Phosphorylation of $\mathrm{I} \kappa \mathrm{B}$ and MAPKs stimulated with rlL-32 $\alpha(100 \mathrm{ng} / \mathrm{ml})$ in RAW 264.7 cells was determined by Western blotting using anti-phospho- $\mid \kappa \mathrm{B}$, -ERK1/2, -p38, and -JNK antibodies. Phosphorylation of $\mathrm{I} \kappa \mathrm{B}$ and ERK1/2 were observed and inhibited by their specific inhibitors, while significant phosphorylation of p38 or JNK. was not observed. This data represents one of three independent experiments.

Additional file 2: Figure S2. Levels of TNF $\alpha$ and IL-10 were expressed as a proportion to that in control culture media without IL-32 $\alpha$ stimulation. Level of TNF $\alpha$ peaked at $12 \mathrm{~h}$ after stimulation with IL-32 $\alpha$ and gradually decreased thereafter, while levels IL-10 kept increasing from 24 to $96 \mathrm{~h}$ after stimulation. Values are expressed as mean \pm SD of triplicate determinations.

\section{Abbreviations}

BM: bone marrow; DHMEQ: dehydroxymethylepoxyquinomicin; DMSO: dimethyl sulfoxide; DSS: dextran sodium sulfate; ELISA: enzyme-linked immunosorbent assay; ERK1/2: extracellular signal regulated kinase1/2; FCS: fetal calf serum; IKB: inhibitor kappa B; IL: interleukin; LPS: lipopolysaccharide; MAPK: mitogen-activated protein kinase; MIP: macrophage inflammatory protein; MyD88: myeloid differentiation factor 88; NF-kB: nuclear factor kappa B; NK: natural killer; NOD: nucleotide-binding oligomerization domaincontaining protein; PBMC: peripheral blood mononuclear cell; PBS: phosphate-buffered saline; PCR: polymerase chain reaction; RA: rheumatoid arthritis; rlL-32a: recombinant human interleukin-32a protein; Tg: transgenic; TLR: Toll-like receptor; TNF: tumor necrosis factor; Wt: wild-type (C57BL/6 JCl).

\section{Acknowledgements}

This work was partially supported by Grants-in-aid for Scientific Research (C) (\#21591959) from the Japan Society for the Promotion of Science.

\section{Author details}

${ }^{1}$ Department of Orthopaedic Surgery, Keio University, 35 Shinanomachi, Shinjuku, Tokyo 160-8582, Japan. ²Department of Pathology, Keio University, 35 Shinanomachi, Shinjuku, Tokyo 160-8582, Japan. ${ }^{3}$ Department of Applied Chemistry, Faculty of Science and Technology, Keio University, Hiyoshi 3-141, Kohoku-ku, Yokohama 223-8522, Japan.

\section{Authors' contributions}

MN carried out the animal and molecular experiments, performed the statistical analysis, and drafted the manuscript. YN conceived and designed the study and edited the manuscript. TK taught the experimental procedure and advised MN on this study. YTa and $\mathrm{KH}$ were involved in the conception and design of the study. AS and YO performed the histopathological examinations. KU provided the reagents to MN. HI, YTo, and TM helped to supervise the study design and provide valuable advice to MN. All authors read and approved the final manuscript.

\section{Competing interests}

The authors declare that they have no competing interests.

Received: 19 December 2011 Revised: 1 May 2012

Accepted: 21 May 2012 Published: 21 May 2012

\section{References}

1. Dahl CA, Schall RP, He HL, Cairns JS: Identification of a novel gene expressed in activated natural killer cells and T cells. J Immunol 1992, 15:597-603.

2. Kim SH, Han SY, Azam T, Yoon DY, Dinarello CA: Interleukin-32: a cytokine and inducer of TNF-alpha. Immunity 2005, 22:131-142.

3. Choi JD, Bae SY, Hong JW, Azam T, Dinarello CA, Her E, Choi WS, Kim BK, Lee CK, Yoon DY, Kim SJ, Kim SH: Identification of the most active interleukin-32 isoform. Immunology 2009, 126:535-542.

4. Goda C, Kanaji T, Kanaji S, Tanaka G, Arima K, Ohno S, Izuhara K: Involvement of IL-32 in activation-induced cell death in T cells. Int Immunol 2006, 18:233-240. 
5. Shioya M, Nishida A, Yagi Y, Ogawa A, Tsujikawa T, Kim-Mitsuyama S, Takayanagi A, Shimizu N, Fujiyama Y, Andoh A: Epithelial overexpression of interleukin-32alpha in inflammatory bowel disease. Clin Exp Immunol 2007, 149:480-486.

6. Netea MG, Azam T, Lewis EC, Joosten LA, Wang M, Langenberg D, Meng X, Chan ED, Yoon DY, Ottenhoff T, Kim SH, Dinarello CA: Mycobacterium tuberculosis induces interleukin-32 production through a caspase-1/IL18/interferon-gamma-dependent mechanism. PLoS Med 2006, 3:e277.

7. Bai X, Kim SH, Azam T, McGibney MT, Huang H, Dinarello CA, Chan ED: IL32 is a host protective cytokine against Mycobacterium tuberculosis in differentiated THP-1 human macrophages. J Immunol 2010, 184:3830-3840.

8. Rasool ST, Tang H, Wu J, Li W, Mukhtar MM, Zhang J, Mu Y, Xing HX, Wu J, Zhu Y: Increased level of IL-32 during human immunodeficiency virus infection suppresses HIV replication. Immunol Lett 2008, 117:161-167.

9. Li W, Sun W, Liu L, Yang F, Li Y, Chen Y, Fang J, Zhang W, Wu J, Zhu Y: IL32: a host proinflammatory factor against influenza viral replication is upregulated by aberrant epigenetic modifications during influenza $A$ virus infection. J Immunol 2010, 185:5056-5065.

10. Smith AJ, Toledo CM, Wietgrefe SW, Duan L, Schacker TW, Reilly CS, Haase AT: The immunosuppressive role of IL-32 in lymphatic tissue during HIV-1 infection. J Immunol 2011, 186:6576-6584.

11. Calabrese F, Baraldo S, Bazzan E, Lunardi F, Rea F, Maestrelli P, Turato G, Lokar-Oliani K, Papi A, Zuin R, Sfriso P, Balestro E, Dinarello CA, Saetta M: IL32, a novel proinflammatory cytokine in chronic obstructive pulmonary disease. Am J Respir Crit Care Med 2008, 178:894-901.

12. Nishida A, Andoh A, Shioya M, Kim-Mitsuyama S, Takayanagi A, Fujiyama Y: Phosphatidylinositol 3-kinase/Akt signaling mediates interleukin-32alpha induction in human pancreatic periacinar myofibroblasts. Am J Physiol Gastrointest Liver Physiol 2008, 294:G831-G838.

13. Nishida $A$, Andoh $A$, Inatomi $O$, Fujiyama $Y$ : Interleukin-32 expression in the pancreas. J Biol Chem 2009, 284:17868-17876.

14. Shoda H, Fujio K, Yamaguchi Y, Okamoto A, Sawada T, Kochi Y, Yamamoto K: Interactions between IL-32 and tumor necrosis factor alpha contribute to the exacerbation of immune-inflammatory diseases. Arthritis Res Ther 2006, 8:R166.

15. Joosten LA, Netea MG, Kim SH, Yoon DY, Oppers-Walgreen B, Radstake TR, Barrera P, van de Loo FA, Dinarello CA, van den Berg WB: IL-32, a proinflammatory cytokine in rheumatoid arthritis. Proc Natl Acad Sci USA 2006, 103:3298-3303

16. Kobayashi H, Huang J, Ye F, Shyr Y, Blackwell TS, Lin PC: Interleukin-32beta propagates vascular inflammation and exacerbates sepsis in a mouse model. PLoS One 2010, 5:e9458.

17. Mun SH, Kim JW, Nah SS, Ko NY, Lee JH, Kim JD, Kim do K, Kim HS, Choi JD, Kim SH, Lee CK, Park SH, Kim BK, Kim HS, Kim YM, Choi WS: Tumor necrosis factor alpha-induced interleukin-32 is positively regulated via the Syk/protein kinase Cdelta/JNK pathway in rheumatoid synovial fibroblasts. Arthritis Rheum 2009, 60:678-685.

18. Ko NY, Mun SH, Lee SH, Kim JW, Kim do K, Kim HS, Her E, Kim SH, Won HS, Shin HS, Kim HS, Kim YM, Choi WS: Interleukin-32a production is regulated by MyD88-dependent and independent pathways in IL-1 $\beta$ stimulated human alveolar epithelial cells. Immunobiology 2011, 216:32-40.

19. Alsaleh $G$, Sparsa L, Chatelus E, Ehlinger M, Gottenberg JE, Wachsmann D, Sibilia J: Innate immunity triggers IL-32 expression by fibroblast-like synoviocytes in rheumatoid arthritis. Arthritis Res Ther 2010, 12:R135.

20. Pan X, Cao H, Lu J, Shu X, Xiong X, Hong X, Xu Q, Zhu H, Li G, Shen G: Interleukin-32 expression induced by hepatitis $B$ virus protein $X$ is mediated through activation of NF-KB. Mol Immunol 2011, 48:1573-1577.

21. Netea MG, Lewis EC, Azam T, Joosten LA, Jaekal J, Bae SY, Dinarello CA, Kim SH: Interleukin-32 induces the differentiation of monocytes into macrophage-like cells. Proc Natl Acad Sci USA 2008, 105:3515-3520.

22. Mabilleau G, Sabokbar A: Interleukin-32 promotes osteoclast differentiation but not osteoclast activation. PLOS One 2009, 4:e4173.

23. Kim YG, Lee CK, Kim SH, Cho WS, Mun SH, Yoo B: Interleukin-32gamma enhances the production of IL- 6 and IL-8 in fibroblast-like synoviocytes via Erk1/2 activation. J Clin Immunol 2010, 30:260-267.

24. Ariga A, Namekawa J, Matsumoto N, Inoue J, Umezawa K: Inhibition of tumor necrosis factor-alpha -induced nuclear translocation and activation of NF-kappa B by dehydroxymethylepoxyquinomicin. J Biol Chem 2002, 277:24625-24630
25. Umezawa K, Chaicharoenpong C: Molecular design and biological activities of NF-kappaB inhibitors. Mol Cells 2002, 14:163-167.

26. Niki Y, Yamada H, Seki S, Kikuchi T, Takaishi H, Toyama Y, Fujikawa K, Tada N: Macrophage- and neutrophil-dominant arthritis in human IL-1 alpha transgenic mice. J Clin Invest 2001, 107:1127-1135.

27. Abu-Ghefreh AA, Masocha W: Enhancement of antinociception by coadministration of minocycline and a non-steroidal anti-inflammatory drug indomethacin in naïve mice and murine models of LPS-induced thermal hyperalgesia and monoarthritis. BMC Musculoskelet Disord 2010, $11: 276$.

28. Chen WT, Mahmood U, Weissleder R, Tung $\mathrm{CH}$ : Arthritis imaging using a near-infrared fluorescence folate-targeted probe. Arthritis Res Ther 2005, 7: R310.

29. Frasnelli ME, Tarussio D, Chobaz-Péclat V, Busso N, So A: TLR2 modulates inflammation in zymosan-induced arthritis in mice. Arthritis Res Ther 2005, 7:R370.

30. Horiuchi K, Kimura T, Miyamoto T, Takaishi H, Okada Y, Toyama Y, Blobel CP. Cutting edge: TNF-alpha-converting enzyme (TACE/ADAM17) inactivation in mouse myeloid cells prevents lethality from endotoxin shock. J Immunol 2007, 179:2686-2689.

31. Heinhuis B, Koenders MI, van Riel PL, van de Loo FA, Dinarello CA, Netea MG, van den Berg WB, Joosten LA: Tumour necrosis factor alphadriven IL-32 expression in rheumatoid arthritis synovial tissue amplifies an inflammatory cascade. Ann Rheum Dis 2011, 70:660-667.

32. Heinhuis B, Koenders MI, van de Loo FA, van Lent PL, Kim SH, Dinarello CA, Joosten LA, van den Berg WB: IL-32gamma and Streptococcus pyogenes cell wall fragments synergise for IL-1-dependent destructive arthritis via upregulation of TLR-2 and NOD2. Ann Rheum Dis 2010, 69:1866-1872.

33. Netea MG, Azam T, Ferwerda G, Girardin SE, Walsh M, Park JS, Abraham E, Kim JM, Yoon DY, Dinarello CA, Kim SH: IL-32 synergizes with nucleotide oligomerization domain (NOD) 1 and NOD2 ligands for IL-1beta and IL-6 production through a caspase 1-dependent mechanism. Proc Natl Acad Sci USA 2005, 102:16309-16314.

34. Novick D, Rubinstein M, Azam T, Rabinkov A, Dinarello CA, Kim SH: Proteinase 3 is an IL-32 binding protein. Proc Natl Acad Sci USA 2006, 103:3316-3321

35. Kim S, Lee S, Her E, Bae S, Choi J, Hong J, Jaekal J, Yoon D, Azam T, Dinarello CA, Kim S: Proteinase 3-processed form of the recombinant IL32 separate domain. BMB Rep 2008, 41:814-819.

36. Rallabhandi P, Nhu QM, Toshchakov VY, Piao W, Medvedev AE, Hollenberg MD, Fasano A, Vogel SN: Analysis of proteinase-activated receptor 2 and TLR4 signal transduction: a novel paradigm for receptor cooperativity. J Biol Chem 2008, 283:24314-24325.

37. Kawai T, Akira S: Toll-like receptors and their crosstalk with other innate receptors in infection and immunity. Immunity 2011, 34:637-650.

38. Choi J, Bae S, Hong J, Ryoo S, Jhun H, Hong K, Yoon D, Lee S, Her E, Choi W, Kim J, Azam T, Dinarello CA, Kim SH: Paradoxical effects of constitutive human IL-32gamma in transgenic mice during experimental colitis. Proc Natl Acad Sci USA 2010, 107:21082-21086.

39. Kang JW, Choi SC, Cho MC, Kim HJ, Kim JH, Lim JS, Kim SH, Han JY, Yoon DY: A proinflammatory cytokine interleukin-32beta promotes the production of an anti-inflammatory cytokine interleukin-10. Immunology 2009, 128:e532-e540.

40. Wang $\mathrm{H}$, Bloom $\mathrm{O}$, Zhang $\mathrm{M}$, Vishnubhakat JM, Ombrellino $\mathrm{M}$, Che J, Frazier A, Yang H, Ivanova S, Borovikova L, Manogue KR, Faist E, Abraham E, Andersson J, Andersson U, Molina PE, Abumrad NN, Sama A, Tracey KJ: HMG-1 as a late mediator of endotoxin lethality in mice. Science 1999 285:248-251.

\section{doi:10.1186/ar3850}

Cite this article as: Nakayama et al:: Enhanced susceptibility to lipopolysaccharide-induced arthritis and endotoxin shock in interleukin32 alpha transgenic mice through induction of tumor necrosis factor alpha. Arthritis Research \& Therapy 2012 14:R120. 